\title{
ÉTICA DEL AMBIENTE NATURAL, DERECHO Y POLÍTICAS AMBIENTALES: TENTATIVA DE UN BALANCE Y DE PERSPECTIVAS PARA EL FUTURO*
}

\begin{abstract}
Alberto Bondolfi**
Resumen: Desde hace tres décadas, a lo menos, en diversos contextos culturales se ha desarrollado una reflexión articulada acerca de la relación buena y justa que el hombre debe mantener con el ambiente natural que lo rodea. Esta reflexión se ha venido estructurando con modalidades diversas, que guardan relación con las diferentes opciones y escuelas que caracterizan la discusión ética y con las diversas tendencias propias de las discusiones relativas al ambiente. Este texto busca examinar y dar cuenta de esta reflexión, intentando identificar con claridad las conexiones internas y las eventuales diferencias.

Palabras clave: medio ambiente; Ética; ética aplicada; ética ambiental; Derecho.

\section{NATURAL ENVIRONMENT ETHICS, LAW AND ENVIRONMENTAL POLICIES: AN ATTEMPT FOR BALANCE}

AND PERSPECTIVES FOR THE FUTURE

Abstract: Upon the last three decades an articulate reflection on the good and fair relationship man have to maintain with the natural environment that surrounds him has been developed in different cultural settings. This reflection has been constructed differently, according with the dfferent options and schools of thought that characterize the ethical argument related to environmental matters. This paper presents and examines that reflection trying to clearly identify internal conextions and eventual differences among distinct trends.

Keywords: environment, ethics, applied ethics, environmental ethics, law.

\section{ÉTICA DO AMBIENTE NATURAL, DIREITO E POLÍTICAS AMBIENTAIS: TENTATIVA DE BALANÇO E PERSPECTIVAS PARA O FUTURO}

Resumo: Há pelo menos três décadas, tem-se desenvolvido em diferentes contextos culturais uma reflexão articulada sobre a relação boa e justa que o homem deve manter com o ambiente natural que o cerca. Esta reflexão tem sido feita de diferentes maneiras e guarda relação com as distintas opções e escolas de pensamento que caracterizam a discussão ética relativa às questões do meio ambiente. Este texto apresenta e examina esta reflexão, tentando identificar com clareza as eventuais conexões e diferenças das diferentes correntes.

Palavras Chaves: meio ambiente, Ética, ética aplicada, ética ambiental, Direito.
\end{abstract}

* Traducido del Italiano por Adelio Misseroni Raddatz

** Profesor del Instituto de Ética Social de la Universidad de Zürich, Suiza

Correspondencia: alberto@sozethik.unizh.ch 


\section{Dificultades en el camino de una ética ambiental como parte de la ética aplicada}

Desde siempre la existencia humana ha estado marcada por su relación con la naturaleza física, tanto propia, a través de la corporeidad, como externa, a través del ambiente natural. Esta relación, extremadamente compleja, ha sido siempre objeto de reflexiones de carácter filosófico y, especialmente, de carácter moral. Las reflexiones relativas a los aspectos éticos han tenido en los últimos decenios un desarrollo extremadamente vasto, bajo la denominación genérica de ética ecológica. Esta expresión evoca una serie de reflexiones muy diferentes entre sí, tanto en los métodos como en los contenidos, pero que en los últimos años han sido objeto de sistematizaciones y de síntesis teóricas de largo aliento (1-7). En este texto trataremos, además, de proponer una especie de cartografía de las posiciones en juego, tomando en consideración también aquellas regiones limítrofes a la ética ecológica propiamente tal y, por ende, tanto a las reflexiones antropológicas como a las socio-jurídico-políticas. Esta actividad de sistematización y tipologización de los argumentos y figuras puestas en evidencia por las varias escuelas y tendencias filosóficas podrá parecer estéril a quien se aproxima a esta problemática desde una militancia práctica en el campo ecológico. Es válida en este ámbito, aun más que en otros, la sentencia schopenaueriana según la cual "Moral zu predigen ist leicht, sie zu begründen schwer"(8).

\subsection{Dificultades "internas" a la reflexión ética y, en particular, al «estatuto de la ética aplicada»}

Entre los problemas vinculados al estatuto de la reflexión moral en cuanto tal, me gustaría evocar en primer término $-\mathrm{y}$ sin pretensión de ser exhaustivo- aquéllos ligados al estatuto epistemológico de la ética aplicada (9 -11). Los métodos de investigación de esta última, así como sus relaciones con la ética general, son altamente controvertidos. Así, es del caso destacar que quienes participan de los debates de ética ambiental no se remiten a una visión unívoca de ésta y tienen en ella expectativas muy diversas entre sí. ¿A qué nos referimos cuando hablamos de ética aplicada y en qué medida las concepciones de esta última pueden tener consecuencias sobre la comprensión de la ética ambiental?

\subsubsection{Acerca del renacimiento de la "filosofía práctica"}

Nace, a partir de la primera mitad de los años setenta, una reorientación de la reflexión ética dirigida a rehabilitar la razón práctica y a ocuparse con mayor atención de problemas normativos en sentido estricto $(12,13)$. Incluso autores que hasta ese momento habían cultivado sólo intereses teóricos ligados al estatuto del lenguaje moral, comenzaron a examinar problemas específicos de ética normativa, destacando aquéllos que podemos llamar clásicos de la ética médica: es de estos años el renacimiento en sede académico-filosófica de los debates -ya conocidos desde hacía tiempo por la teología moral y por la discusión jurídica-relativos al aborto, a la eutanasia, a los transplantes de órganos y a otros temas afines.

A este respecto comienzan a delinearse, cada vez con mayor precisión, dos frentes o escuelas, vinculados precisamente a dos diversas respuestas frente a la interrogante sobre los fundamentos de las normas morales concretas: los denominados deontológico y teleológico $(12,13)$. Ante todo, debemos destacar que estas corrientes han sido claramente separadas al definirlas y considerarlas en su idealidad típica. Sin embrago, en las discusiones en curso, estas escuelas se manifiestan en una serie de "formas mixtas» dado que sus integrantes están conscientes de que sostener estas posturas en su pureza, a ultranza, puede llevar a situaciones grotescas y absurdas. La pareja argumentativa de la fundamentación deontológica o teleológica de las normas está ligada a la diversa consideración de las consecuencias de los actos o, respectivamente, de las normas mismas.

- En la ética deontológicamente fundada los deberes valen en símismos ya que son generalizables o universalizables, independientemente de las consecuencias fácticas o ideales que su cumplimiento pueda provocar. El "punto de vista moral" parece ser independiente de una valoración de las consecuencias.

- En la teleológica, en cambio, la moralidad de los actos o de las reglas es juzgada, precisamente, por una consideración de las consecuencias, tanto de los primeros como de las segundas. 
El interés por la ética aplicada no sería comprensible en nuestros días si no hubiese sido precedido por otro cambio de interés, desde los problemas metodológicos de metaética a los específicos de ética normativa.

Un factor ulterior que explica la actualidad de la discusión en torno a la ética aplicada está dado por el renacimiento del interés, tanto en Filosofía como en Teología, por la llamada casuística(16 19) como forma de concretización de la ética aplicada. Esta palabra designa formas de reflexión moral muy distintas entre sí y diversamente ubicables en la historia del pensamiento moral, pero aunadas por algunas características que las hacen particularmente actuales. Sin querer entrar aquí en el mérito de un tema fascinante, pero sólo cercano a aquél que queremos tratar, me limito a designar con la expresión casuística una forma de reflexión moral hecha a partir de la presentación de un conflicto concreto en el cual $-\mathrm{y}$ he aquí el carácter peculiar del ejercicio- las consecuencias fácticas de la historia narrada en el «caso» son «probables» y/o las normas que han de aplicarse en tal caso son también «probables».

En esta vertiente, la casuística se aproxima, sin identificarse, al programa de la llamada ética aplicada. En ambas se busca una ganancia cognoscitiva obtenida no a través de deducciones rigurosas a partir de los principios - pasando por las normas generales y llegando hasta la conflictualidad de la situación concreta-, sino que se hace fe de las posibilidades ínsitas en la inducción, como el procedimiento más adecuado para resolver, precisamente, tales conflictos (20). El caso particular no es sólo una concretización de principios abstractos, sino que la reflexión acerca de éste provoca una ganancia cognoscitiva que no es posible lograr con otros medios cognoscitivos. La referencia a la experiencia vivida $(21,22)$, si bien mediada por la reconstrucción narrativa, no tiene sólo una función ejemplificadora o didáctica, sino que deviene en constitutiva de la comunicabilidad de la conflictualidad moral.

Me permito evocar entre los factores que han facilitado la recuperación de la ética aplicada, también al movimiento neoaristotélico $(23,24)$. La contribución de este movimiento reciente se hace patente, sobre todo cuando, a través de la distinción entre accionar técnico y accionar estratégico, por una parte, y accionar moral por la otra, se evidencian algunos momentos y algunas características específicas del momento aplicativo en ética. La misma observación puede ser hecha cuando, en las publicaciones de ética aplicada, el tema de la prudentia y de la epikeia se torna central. Los factores hasta ahora enunciados hacen plausible el surgimiento de un interés específico por la ética aplicada, pero no explicitan todavía los elementos centrales.

\subsection{2 ¿Qué se entiende hoy por ética aplicada?}

Para poder evidenciar claramente cuáles son las posiciones posibles al concebir las características específicas de la ética aplicada y las tareas a ella conexas, trataremos de sostener la hipótesis de la existencia de modelos ideal-prácticos con carácter intencionalmente «extremo», para así establecer el abanico dentro del cual ellos se mueven. Estos modelos ideal-típicos no son sostenidos en su forma «pura», sino en modelos adaptados en forma más o menos pragmática. Ellos mantienen, por lo menos en la economía de esta exposición, un significado pedagógico que busca evidenciar la peculiaridad del problema de la aplicación en ética (25).

- Un primer modelo «extremo» ve en el momento aplicativo sólo una mera deducción a partir de principios éticos considerados suficientemente fundados. Se sostiene, siempre al interior de este modelo hipotético, una construcción geométrica del saber moral, en el cual las proposiciones concretas no son otra cosa que explicitaciones de aquello que se encuentra ya esencialmente contenido en las proposiciones generales que caracterizan los principios éticos. Siempre al interior de tal visión, la ética aplicada no puede ser productora de verdadero «nuevo saber», ya que la operación de aplicar, en su carácter exclusivamente deductivo, no aporta ningún elemento sustancialmente nuevo al saber moral.

- En el otro extremo del área que aquí se pretende delimitar, se enfatiza el carácter novedoso ligado a cada nueva aplicación en ética. Se subraya cómo una cantidad de problemas fácticos, como por ejemplo la explosión demográfica o la crisis ambiental, exigen «nuevas respuestas». Ellas deben ser «nuevas» no sólo en el sentido de reclamar nuevas concretizaciones de principios morales ya conocidos, sino que de una reconsideración radical de los principios mismos. En otras palabras, a nuevos problemas deben corresponder nuevas teorías éticas. 
Esta tendencia, si es aplicada constantemente, lleva evidentemente a una "pulverización» de los discursos de filosofía moral que niega cualquier analogía entre los diversos conflictos morales y los diversos sectores de la vida aquí examinados.

Estas dos modalidades evidentemente no son sostenidas en su extrema crudeza, sino que en variaciones en gran medida moderadas. Se trata ahora de ver cuál es el punto medio teóricamente más coherente y que, al mismo tiempo, dé mejores frutos a nivel operativo. A este respecto resulta especialmente útil detenerse brevemente en torno a la distinción entre el momento de fundar y el de aplicar (26), caracterizando la ética aplicada como aquella área en la cual la operación de aplicar encuentra toda su concretización.

En su contenido más general, la distinción ya se encuentra presente en la hermenéutica clásica (27), pero hoy encuentra nuevas explicitaciones y precisiones directamente relacionadas con la teoría ética. En este contexto, fundar una norma moral indica sobre todo el conjunto de operaciones intelectuales tendientes a encontrar razones de principio que militen a favor o en contra de ella. En cambio, aplicar (28) indica-siempre en este contexto preciso- la búsqueda de argumentos a favor o en contra de la elección de una norma concreta para valorar normativamente una situación de conflicto para el accionar humano.

$\mathrm{Al}$ interior de la ética filosófica se perfilan dos tipos de modelos ideal-típicos al considerar las funciones del fundar y del aplicar. Estos modelos se remiten, en sus aspectos generales, a la filosofía de Aristóteles y de Kant, aunque ellos han sido desarrollados y articulados, además, por varios discípulos de ambos filósofos.

En el universo del Estagirita, la aplicación de normas individuales a situaciones distintas es una operación relativamente fácil, por una serie de motivos internos a su pensamiento. El accionar humano se mueve, en la perspectiva aristotélica, al interior de un cuadro antropológico prefijado, aunque no predeterminado. El sujeto humano establece sus acciones y sus elecciones no a partir de una autonomía que lo hace soberano y, al mismo tiempo, «indiferente» en relación con las opciones operativas posibles, sino que a partir de predisposiciones innatas y esencialmente inherentes a su ser hombre. Estas predisposiciones, llamadas inclinationes naturales en el lenguaje de la tradición aristotélico-tomista (29), no convierten al hombre en una especie de autómata, sino que determinan el marco en el cual se colocan sus opciones libres. La autonomía del hombre que actúa se encuentra preestructurada por una «teleología natural» que lo dispone y lo lleva al fin último de la felicidad. Sin querer entrar aquí en los problemas internos de la ética aristotélica, se puede, no obstante, notar cómo este cuasi naturalismo aristotélico representa, al mismo tiempo, una ventaja y una dificultad para nuestro tema de la ética aplicada y para sus repercusiones en ética ambiental.

La ventaja consiste en que las inclinationes naturales hacen más fácil la elección concreta de las normas aplicables, ya que éstas son una explicitación, en el ámbito de la racionalidad específica del accionar humano, de tendencias ínsitas en la naturaleza corpóreo-espiritual del hombre. $\mathrm{Si}$ a ello se añade el hecho de que Aristóteles tiende fácilmente a considerar como «naturales» una serie de instituciones sociales fundamentales como la familia y la polis, se entiende cómo las operaciones de aplicación le resultan particularmente fáciles.

La dificultad es, en cambio, de tipo metodológico y está ligada a la sensibilidad, del todo moderna, de no querer caer en la "falacia naturalista" (30). Cuando alguno de nosotros aplica una norma a una situación particular, elabora -más o menos conscientemente- una serie de subsunciones y de clasificaciones. Estas operaciones mentales se orientan a interpretaciones de la realidad preexistentes en nuestra mente. Estas últimas, no deben, sin embargo, ser supuestas, como si fuesen realidades «naturales», ya que en este caso su relevancia normativa no podría descender directamente de ellas.

La filosofía aristotélica ha dado, no obstante, otra decisiva contribución a la problemática de la aplicación en filosofía moral. Se trata de la doctrina de la phronesis, o de la latina prudentia, en cuanto capacidad, hábito operativo o virtud de concretizar las exigencias morales en una situación precisa, tomando en consideración tanto las normas generales que anteceden a la interpretación del conflicto en juego, como las modalidades concretas en las cuales se manifiestan las circunstancias (31).

En el pensamiento kantiano, la relevancia dada al momento aplicativo no asume la misma relevancia que en el pensamiento del Estagirita. La atención del filósofo de Königsberg se concentra casi completamente en el momento fundante. Gracias a ello el juicio moral puede pretender validez 
intersubjetiva y universal. Evidentemente, el filósofo alemán conoce y aprecia también el momento de la aplicación de la norma moral a una situación concreta. La capacidad que preside en este ámbito es la del Urteilskraft. No obstante, ella no puede llegar hasta el punto de tener que invalidar, en casos de conflictos particulares, la validez universal de la norma bien fundada. Es apreciable, por lo tanto, en Kant un "rigorismo fundante" en el cual el momento de la aplicación es visto casi con sospecha, ya que podría poner en discusión el carácter universal de las normas. La escasa «aplicabilidad» de la ética kantiana se debe en gran parte, por ende, a su radical antinaturalismo.

El debate acerca del momento aplicativo en ética ha puesto en evidencia el hecho que las racionalidades en acción en los diversos sectores de la vida y en los diferentes niveles en que son analizadas y juzgadas, son entre ellas análogamente diversas. Esta diversidad impide una transposición mecánica de un principio moral de un sector a otro.

No obstante, debe destacarse el hecho de que son siempre sujetos considerados capaces de responsabilidad moral los que actúan en los diversos sectores de la vida y en los diversos niveles en que ella se manifiesta. Es tarea de la reflexión ética poner en evidencia tanto la diversidad de los ámbitos de aplicación como la continuidad de los sujetos agentes, incluso cuando estos últimos son supuestos como «débiles». Con el fin de que tales afirmaciones no sean estériles en su generalidad, he decidido mostrar la pertinencia en un sector preciso, pensando así dar a éstas mayor pertinencia.

\subsection{3 Ética aplicada y ética ambiental}

Se trata de ver ahora cómo las consideraciones hechas en torno a la denominada ética aplicada, también pueden encontrar parcial concordancia en el ámbito particular de la ética del ambiente.

Las dificultades evocadas más arriba, aumentan ulteriormente si estimamos que la ética ambiental puede ser considerada como una ética aplicada a la segunda potencia, a lo menos por dos motivos.

En primer término, se considera en ética ambiental informaciones y contenidos que se remontan a otras éticas aplicadas como la ética económica o política y se busca hacerlas operativas poniendo énfasis en exigencias específicas del ambiente natural.

Las exigencias morales en ética ambiental deben poder encontrar ulteriores aplicaciones o, si se quiere, una "aplicación de regreso" en estos sectores clásicos de la reflexión moral. Además, se puede ver cómo la ciencia ecológica misma es una forma de saber combinatorio en el cual confluyen resultados provenientes de varias disciplinas, tanto empíricas como reflexivas.

La ética ambiental representa, además, una forma de ética aplicada cuyas argumentaciones pueden llevar a conflictos normativos con exigencias morales defendidas en otros ámbitos. Así, podemos apreciar cómo las relaciones entre argumentos usados en ética ambiental y en ética médica o en bioética no son siempre armoniosos o coherentes, sino más bien fuentes de ulteriores malentendidos (32). Lo mismo vale para la cuestión animal, según veremos más adelante, que no puede ser reducida a un simple subproblema de ética ambiental, sino que manifiesta valencias propias y no desprovistas de dificultades, si la analizamos en conexión con temas y argumentos exclusivamente ambientales.

\section{Especificidad "moderno-tardía" de la relación hombre-naturaleza}

Desde siempre el hombre ha sentido la necesidad de mantener no sólo relaciones materiales "de uso" con la naturaleza que lo rodea, sino también de dar a estas relaciones un valor simbólico, es decir, de dar a ellas un significado. Esta actividad ha proseguido después de la revolución científica que se produjo en el siglo XVII con Galileo y Newton y de la industrial, a partir de la segunda mitad del siglo XVIII. En las dos revoluciones señaladas, el hombre, a nivel individual y colectivo, modificó su relación con el ambiente natural, tanto a nivel fáctico como intelectual, reformulando incluso las percepciones que él tenía de eventuales deberes en relación con este mundo natural. Las transformaciones producidas en los últimos decenios de nuestro siglo, levantan en muchos de nosotros la sospecha de encontrarnos en una situación de nuevo salto cualitativo en relación con la relación hombrenaturaleza.

Por este motivo, hay quienes consideran adecuado hablar de situación postmoderna también a propósito de nuestra problemática. La reciente revolución informática parece haber transformado radicalmente nuestra manera de producción material y simbólica, de manera tal de hacer caer los 
parámetros que sostenían la visión moderna del mundo (33-35). El hombre parece haber dado vuelta las relaciones entre causas y efectos y considera su propio mundo tecnificado como el "más natural posible". Sin querer negar el impacto cualitativo producido en estos últimos años en la relación hombre-naturaleza, pienso que es más correcto caracterizar el tiempo actual como modernidad tardía, ya que no están todavía suficientemente visibles los caracteres del tiempo que se está develando ante nuestros ojos.

Se podría objetar a este respecto que otro desafío lleva a caracterizar nuestra edad como "postmoderna". Sólo hoy, en efecto, se nos presentan desafíos ambientales que traspasan los confines de la cultura occidental para llegar a un nivel planetario. Problemas ambientales se manifiestan incluso en áreas culturalmente muy distintas a la nuestra, como Japón o China, pero que no pueden ser definidas como preindustriales. La universalidad del fenómeno de la industrialización y la particularidad cultural de las diversas percepciones y valoraciones de la naturaleza son un problema central de toda ética del ambiente que no pretenda ignorar completamente la variable socio-cultural y las interpretaciones particulares de los fenómenos vinculados al ambiente.

Sin perjuicio de reconocer la urgencia de una reflexión de este tipo, no podemos dejar de dar, aunque sea sucintamente, un vistazo histórico-doctrinal, en el ámbito particular y específico de las tradiciones judeo-cristianas, para tomar conciencia de los eventos que se han suscitado, para saber localizar las "nuevas evidencias" con las cuales convivimos y que hasta hace poco tiempo eran todavía impensables (36).

\subsection{Visión judeo-cristiana del cosmos y nacimiento de la cuestión ambiental}

La necesidad de una reconstrucción histórico-moral de los temas vinculados al precepto veterotestamentario del «dominium terrae» (Gn 1:28) y de su recepción en el ethos cristiano, fue afirmada hace tiempo (37). No se trata de un problema pertinente sólo para la teología, sino que, visto que el diagnóstico de la causa de la insensibilidad ambiental ha venido desde el exterior, esto es, desde la reflexión filosófica en torno a las percepciones contemporáneas de la naturaleza, será necesario tratar de verificar la pertinencia de tal reproche en una perspectiva no sólo intrateológica sino que mucho más global, teniendo presentes los efectos del mensaje bíblico sobre las mentalidades colectivas incluso más allá del ámbito específico de la teología y de las comunidades eclesiales.

La relación entre historia del cristianismo y cuestión ambiental fue formulada por primera vez en un ensayo de L. White ( 38 - 40) en términos muy generales $(41,42)$. Precisamente este carácter genérico - pero al mismo tiempo macizo de la tesis de White- que pretende hacer responsable del desastre ambiental contemporáneo, en su totalidad, a la visión judeo-cristiana del mundo, ha provocado una serie de respuestas de precisión y de recusación, primero en los Estados Unidos y después en Europa, especialmente Alemania. White afirmaba que la doctrina de la encarnación del Verbo es responsable de una desacralización de la naturaleza, percibida hasta el cristianismo como "creación" y ahora, en cambio, disponible para el hombre y sus intervenciones.

Ya Passmore (38), retomando críticamente la tesis de White, precisa algunos elementos que resultan muy genéricos en la versión de este último. Así, la "arrogancia cristiana" del primero se transforma en la arrogancia de su versión helenizada y secularizada. Este autor subraya la diversidad entre la sensibilidad judaica y cristiana frente a la creación natural y afirma que el "origen de la actitud 'arrogante' del cristianismo hacia la naturaleza debe buscarse en la separación del hombre de la naturaleza y en la idea de que la naturaleza fue creada especialmente para él, concepciones éstas propiamente cristianas, no en el concepto de 'dominio del hombre'del Antiguo Testamento',42; p.27). Además, precisa el rol negativo del proceso de helenización afirmando perentoriamente que "sobre esto, los críticos tienen razón: el cristianismo ha impulsado al hombre a considerarse patrón absoluto de la naturaleza, el ser al cual le fue confiada toda la creación, pero se equivocan cuando concluyen que esto deriva de la enseñanza de la religión hebrea. Los orígenes verdaderos de esta idea están en Grecia"(42; p.29).

Las precisiones de Passmore no impidieron la aceptación genérica de White también en Europa, con precisiones específicas y vinculadas con las preocupaciones de otros autores. Quisiera evocar aquí brevemente sólo las de C. Amery (43) y de E. Drewermann como representativas de esta aceptación centroeuropea. El primero de estos 
autores subraya el rol destructor del ethos cristiano, tanto en su variante protestante-puritana, dirigida al éxito económico como signo indirecto de pertenencia a la comunidad de los redimidos, como en la católica, dirigida a recoger a través de "buenas obras" méritos para la salvación eterna. Las raíces comunes de esta actitud, que lleva a mantener una relación puramente instrumental con las realidades naturales, deben buscarse, siempre según Amery, en la actitud ya presente en el monaquismo occidental que despreciaba el valor intrínseco de la naturaleza no humana, reduciéndola a puro instrumento de supervivencia para el hombre o al máximo interpretándola como "signo" de las realidades mucho más esenciales, es decir, de aquellas invisibles y espirituales.

Drewermann (44), por su parte, retoma diagnósticos análogos, presentándolos, en todo caso, como crítica teológica inmanente al antropocentrismo exclusivo que, a su juicio, caracteriza el mensaje judeo-cristiano desde el Antiguo Testamento. Una eventual y deseable corrección de tal tendencia puede producirse, según Drewermann, sólo si el cristianismo está dispuesto a profundizar el rol religioso mediato desde el conocimiento de los estratos profundos de nuestra psiquis y si está en condiciones de asimilar al interior de la propia reflexión teológica elementos provenientes de otras religiones, sobre todo con trasfondo animista. Sólo una visión animista de la creación lleva al hombre a comportarse con respeto hacia la naturaleza que lo rodea.

Todas estas críticas - que he evocado sólo de manera sucinta- han impulsado a la investigación teológica a contraatacar y, especialmente, a investigar con mayor precisión en la propia tradición histórica, para suavizar el reproche en la medida que se revele fundado y a proponer interpretaciones más documentadas de la propia tradición en el plano de los textos y de su Wirkungsgeschichte y, por ende, tanto de la historia de sus efectos sobre las mentalidades corrientes como sobre las doctrinas teológicas en cuanto tales.

En esta perspectiva, la necesidad de una reconstrucción histórico-moral de los temas vinculados al precepto veterotestamentario del «dominium terrae» (Gn. 1: 28) y a su recepción en el ethos cristiano ha sido afirmada desde hace tiempo (21), por lo menos como postulado genérico.

A partir de 1979 se hizo posible la publicación de Krolzik que tuvo en pocos meses el reconocimiento de una segunda edición (45). Como dice el título, se trata de un libro de carácter monográfico, casi una «tesis», dirigido a dar respuesta a la pregunta, formulada a menudo de manera simplista, de si el judeo-cristianismo es directamente responsable del comportamiento destructivo frente a la naturaleza. El libro está compuesto de dos partes, una primera descriptiva del fenómeno, y la segunda centrada particularmente en el análisis de las doctrinas en la historia de la moral. Me detendré en esta última, pues me parece presenta la perspectiva original del volumen.

Ésta se remonta a Descartes, para individualizar las raíces de su comprensión de la realidad y de las leyes de causalidad ya en el sigo XII, con las escuelas de París y de Oxford. El autor no se interesa, sin embargo, sólo en la cosmología, sino que también en la historia de la técnica, viendo las raíces de su desarrollo en la edad moderna a partir del temprano medioevo, con la introducción de nuevos sistemas agrícolas y el desarrollo de instrumentos particulares (el molino de agua, el perpetuum mobile y el reloj mecánico). Las premisas «ideológicas» para este proceso pueden encontrarse en una «estructura de plausibilidad» (Krolzyk media esta categoría desde P. Berger y Th. Luckmann) de tipo teológico, propia de la tradición latina. En la citada monografía, se refiere sobre todo a los siguientes lugares teológicos: la concepción del tiempo y de la historia, la valorización del trabajo manual, la relación hombre-naturaleza en la exégesis de Gn. 1:28. En lo que se refiere al primer tema, el autor hace notar cómo la concepción de la renovación histórica como "reformatio in melius» ha influenciado la teología occidental a partir de Tertuliano, más aún que en la teología bizantina que ve el tiempo como posibilidad restauradora de la situación primitiva de la humanidad.

Sobre todo las teologías radicales del medioevo -el autor se detiene particularmente en Gioacchino da Fiore- han puesto en evidencia cómo nuestros tiempos futuros son vistos como «nueva creación». En cuanto a la valorización del trabajo manual, Krolzik subraya la contribución específica del monaquismo occidental, que revaloriza perspectivas veterotestamentarias. También la recepción del nuevo testamento sobre este punto muestra diferencias en oriente y occidente: el autor lo muestra a partir de los diversos comentarios hechos a la pericope sobre Marta y María (Lc 10:38-42). El libro concluye con la formulación de la tesis histórica 
que está en la base de toda la publicación: Gn 1:28 ha comenzado su acción legitimadora frente al desarrollo de la técnica, no a partir de Bacon y Descartes, sino ya desde el medioevo, por obra sobre todo de Ugo di S. Vittore. El aprovechamiento desenfrenado de la naturaleza ha tenido lugar, empero, sólo en el ámbito de la versión secularizada del mandamiento de Gn 1:28 y no puede, por ende, ser atribuida de manera exclusiva al texto bíblico en su recepción milenaria.

Esta tesis se prestaría para discusiones y diferenciaciones ulteriores. Sin embargo, ello no quita nada al valor de esta monografía, muy útil en su aporte informativo. No queda más que desear la prosecución de investigaciones detalladas que profundicen singulares aspectos, figuras y períodos de esta compleja problemática. Krolzik mismo, en una segunda publicación (46), ha profundizado ulteriormente su propia tesis, deteniéndose especialmente en el período de la temprana modernidad, visto como período clave para el surgimiento de la llamada arrogancia con trasfondo cristiano frente a la naturaleza. La doctrina de la providencia ha reforzado de manera decisiva la comprensión moderna del ambiente natural. En este contexto, se continúa por admitir que Dios gobierna el mundo a través de las leyes de causalidad que Él mismo ha fijado para su gubernatio mundi. El hombre, en la misma medida que se relaciona con tales leyes naturales, prolonga el gobierno divino sobre la naturaleza. De este modo, también la teología moderna, sin ser directamente la causa del desarrollo tecnológico, lo acompaña en sentido positivo y contribuye, por ende, indirectamente al nacimiento de un ethos que ve en la intervención tecnológica algo más positivo que dejar simplemente a los fenómenos en su naturalidad. Krolzik admite, por lo tanto, que el verdadero salto cualitativo en la actividad de aprovechamiento de la creación no se produjo todavía de manera plena en la edad de la visión mecanicista de la naturaleza (siglos XVII y XVIII), sino que a continuación de la secularización más plena en el siglo XIX, luego de la introducción de la teoría darwiniana de la evolución de las especies vivientes.

La situación de la investigación histórica, tal como se presenta a fines de los años $90(47,48)$, no me parece estar todavía en grado de responder de manera adecuada a las interrogantes vinculadas a la interpretación del dominium terrce. Mucho trabajo de análisis queda todavía por hacer, aunque podemos apreciar una cierta convergencia entre los autores, en orden a no considerar sólo a la tradición bíblica como el único factor que ha generado la actitud tardo-moderna en relación con el ambiente natural. La tesis de White y de aquellos que lo han seguido en Europa, es muy simplista, aunque como medio de disuasión ha servido para iniciar un debate que reclama todavía contribuciones clarificadoras de peso. Incluso el conocimiento de ulteriores factores, por sí solo, no estará en grado de dar una respuesta adecuada al problema, ya que la respuesta correcta consistirá muy probablemente en la combinación compleja de estos factores. Además, a través de estudios comparativos con civilizaciones no occidentales, tal vez se podrán localizar otros factores culturales todavía no directamente visibles a simple vista en este momento.

\subsection{Especificidades vinculadas a la modernidad tardía}

Varios son los elementos que caracterizan la relación entre hombre y naturaleza en la modernidad tardía de nuestro siglo, especialmente en los últimos decenios que ven surgir un poder tecnológico no sólo en relación con la materia no viviente, sino también en relación con el ser vivo mismo, a todos los niveles. Estos elementos no son localizables para ser examinados en su surgimiento y en sus transformaciones.

- $\quad$ Entre estos pasajes salta a la vista, en primer término, la diversa percepción que el hombre premoderno y el contemporáneo tienen del peligro constituido por los fenómenos naturales. Si en el primer caso él piensa que se encuentra frente a catástrofes ciegas o hasta "castigos de Dios" (49,50), en el segundo no niega el carácter de peligro, pero lo califica como "riesgo" (51-55). El temor permanece de manera constante en la relación hombre-naturaleza, pero éste es percibido de manera cualitativamente diferente $\mathrm{y}$, así, la conciencia de una eventual responsabilidad moral en relación con tales fenómenos, cambia.

- Nuestra relación se encuentra siempre más vinculada a la mediación de la técnica (56). A través de ella, el hombre busca evitar los fenómenos que considera negativos y a ella se encomienda también la respuesta en términos de eficacia. Así, hemos 
creado instrumentos de verdad eficientes, pero de los cuales conocemos sólo parcialmente los efectos colaterales negativos. A pesar de que la introducción de novedades técnicas a nivel masivo ha sido sometida a "rituales sociales de preparación y control" (como los comités de Technology Assessment), en ciertos casos tenemos que servirnos de estas técnicas antes de haber obtenido un conocimiento óptimo de todos los efectos colaterales que ellas podrían provocar.

- Por demás, el hombre mantiene con la mediación técnica una relación a un nivel todavía más "intrahumano". Cada vez confía más decisiones con connotaciones sociales y políticas a la ayuda técnica de máquinas siempre más complejas y que, de manera creciente, imitan la estructura mental humana. Los últimos desarrollos de la informática hacen cada vez más tenue la distinción de principio entre hombre y máquina, con consecuencias no sólo para la factibilidad de las decisiones así tomadas, sino también para la reflexión a nivel de principios (57,58).

- $\quad$ En fin, la experiencia misma que el hombre tiene de la naturaleza, asume caracteres siempre más "artificiales". Los niños de las grandes ciudades que encuentran animales sólo en los zoológicos, piensan realmente que se encuentran "in natura" y no sólo en un universo metafóricamente "natural".

Todos estos nuevos elementos que caracterizan la reciente relación del hombre con el ambiente natural, se han interiorizado tan velozmente, no sólo en la psiquis de los individuos, sino también en las mentalidades colectivas, de manera tal que cualquier cambio de comportamiento, considerado necesario desde un punto de vista moral, deberá tener debida cuenta de este carácter indirecto y metafórico de la relación señalada. Cualquier apelación a un pretendido "retorno a la naturalidad de los fenómenos" no puede ser clasificada mas que como ingenua e irrealista. Nuestra relación con la naturaleza permanecerá, por ende, constantemente vinculada a la mediación de la técnica y a la artificialidad indirecta debida a nuestras mismas intervenciones precedentes sobre los elementos de la naturaleza. Estas constataciones nos deben llevar a una consecuencia de método en relación con la elaboración de una ética ambiental a la altura de los desafíos contemporáneos.
Si nuestra relación con el cosmos que nos rodea deviene interrogante moral, ello se debe a que, a través de nuestras mediaciones técnicas, la transformación de la realidad natural comporta al mismo tiempo una mutación en los hombres al interior de nuestras sociedades. En otras palabras, aun cuando en el ámbito de la ética ecológica hiciéramos referencia a criterios no antropológicos, sigue siendo evidente una opción antropocéntrica indirecta que permanece inherente a cualquier discurso que se quiera proponer en este ámbito.

\section{Figuras argumentativas en ética ambiental}

Un examen desapasionado de la extensa literatura contemporánea sobre ética ambiental nos muestra que los argumentos esgrimidos para justificar una intervención correctiva en relación con las mutaciones que nosotros mismos hemos provocado en el ambiente natural, no se limita a la sola constatación de la centralidad del hombre en el cosmos, sino que apela también a otras figuras argumentativas y a otros estímulos. En la tentativa de poner un mínimo de orden en todo este material de motivos y de argumentos, nos damos cuenta de que existen niveles de reflexión muy diversos entre sí, aunque no fácilmente distinguibles. Propongo aquí una tipología tripartita que, no obstante sus imperfecciones, por lo menos servirá para encuadrar de mejor manera nuestro trabajo:

- Debemos señalar, en primer término, que nos encontramos con diversas imágenes o percepciones del mundo que en sí mismas no comportan todavía ninguna preferencia normativa concreta a favor de particulares mandamientos o prohibiciones, pero que predisponen a percibir, en un modo o en otro, los problemas y las contradicciones vinculadas al ambiente natural. Aquel que defienda una imagen precisa del mundo, verá algunos problemas morales como pertinentes o ilegítimos y quien defienda otra, cambiará las prioridades que debe defender.

- $\quad$ En un segundo nivel de concretización se sitúan las normas éticas concretas y los sistemas normativos que las legitiman. Estas proposiciones están estrictamente vinculadas con las imágenes del mundo a que nos acabamos de referir, pero no son tan dependientes de ellas como para tener que postular un vínculo intrínseco entre el primer y el segundo nivel. Así, por ejemplo, los adeptos a una imagen del cosmos que prevé un Dios creador, no necesariamente defienden las mismas opciones 
morales en el campo ecológico.

- En fin, en un tercer nivel, se sitúan afirmaciones, también con carácter normativo, pero que se distinguen por tener un carácter estratégicopolítico o normatividad jurídica. También este nivel está íntimamente vinculado a los otros dos, pero no se confunde con ellos, manifestando así su especificidad. Nuestra atención, en este estudio, se concentrará, precisamente, en este tercer nivel, tratando de poner en evidencia sus peculiaridades, especialmente desde una perspectiva ética $(59,60)$.

El debate ético-ecológico recurre constantemente a estos tres niveles de la reflexión, mediante confusiones y sobreposiciones que lo hacen siempre perfectible. Podemos constatar que muchas posiciones hoy imperantes en el debate público tienden a pasar muy velozmente desde el primer al tercer nivel, es decir, desde las imágenes globales del mundo a las estrategias jurídicopolíticas, sin una mediación ética propiamente dicha. Por este motivo, la mayor parte de las síntesis de ética ambiental actuales (61) buscan ante todo proponer una tipología sobre los argumentos éticonormativos para caracterizar mejor la especificidad de la reflexión ética en este ámbito. Las retomo sintéticamente en una forma que se ha hecho casi "canónica", con la sola intención de informar y orientar, antes de pasar al centro de mis consideraciones y, por ende, a una reflexión sobre algunos componentes morales de las estrategias políticas y jurídicas.

- Con el término antropocentrismo se designa una visión del mundo en la cual se establece una diferencia de principio entre el hombre, como individuo y como especie, y la naturaleza que lo rodea. No obstante ser él mismo -a través de la propia corporeidad- parte de esta naturaleza, se diferencia de ella por la capacidad de formular y hacer de esta naturaleza una finalidad en relación con él. Esta relación de finalidad no excluye, sin embargo, que el hombre se encuentre en condiciones de formular deberes que tienen como posible objeto también la naturaleza circundante. Estos deberes, sin embargo, son legitimados a través de una referencia, directa o indirecta, a la finalidad antropocéntrica antes citada.

- Como biocéntrica es designada, en cambio, aquella concepción del cosmos en la cual no se establece jerarquía alguna, ni de hecho ni mucho menos de derecho, entre las diversas especies vivientes. Tal concepción es defendida por varios autores, pero es difícilmente "pensable" en las diversas manifestaciones de la vida cotidiana del hombre.

- La posición pathocéntrica no sostiene, en línea de principio, una visión precisa del cosmos. Ella propone, en cambio, un criterio de decisión sobre el cual fundar y dirimir los conflictos normativos entre las exigencias de la vida humana y animal. Este criterio es individualizado en la realidad del dolor, que es minimizado donde quiera que él se manifieste, independientemente de la especia animal o humana a la cual el sujeto sufriente pertenece.

- La visión fisiocéntrica, por último, favorece una ética ecológica bastante cercana a la biocéntrica. Sin embargo, de manera específica es defendido un carácter sagrado de la naturaleza que la acerca a una visión animista de toda la realidad.

Todas estas posiciones no son, evidentemente, identificables en una forma "pura", sino en versiones más o menos "mixtas", en las cuales argumentos diversos asumen un peso más o menos decisivo. Los actores políticos que son llamados a legislar en el ámbito ambiental no podrán, evidentemente, echar mano a una única forma argumentativa (62), considerándola como prevalente en campo ético, sino que tendrán que tomar en cuenta que todo este terreno está en constante movimiento y no exento de problemas. Se puede intentar aquí una primera tipología:

- En primer término, existen problemas comunes a cada tipo de argumentación en ética ambiental. Como bien puede verse, cada vez que se habla de "vida" o de "dolor" o de "naturaleza", se usan estos conceptos en sentido fuertemente analógico, de modo tal que las consecuencias normativas no siempre son plausibles o fácilmente deducibles de similares categorías.

- Otros problemas se encuentran, en cambio, vinculados específicamente a las singulares orientaciones citadas más arriba. Así, las posiciones biocéntricas o fisiocéntricas no reconocen suficientemente el carácter estructurado y jerarquizado del ser vivo, inserto en un complejo mecanismo de selección de las especies en particular y piensan que es posible, tanto en los hechos como en los principios, defender una maximización de toda forma de vida, sin que las otras deban soportar daño alguno. Además, tales posiciones deben reconocer que el simple hecho de querer dar significado a fenómenos naturales, es imposible sólo 
a partir de una perspectiva particular como lo es, precisamente, la del hombre.

- $\quad$ La posición pathocéntrica, por su parte, tiene también dificultad para admitir el carácter analógico del concepto de dolor, que puede pasar del simple fenómeno fisiológico a una manifestación psíquica posible sólo en el hombre. Además, el factor dolor, si bien relevante incluso en una perspectiva antropocéntrica y valorado culturalmente de manera diversa según los contextos (63-68), debe ser sopesado conjuntamente con otros factores también moralmente relevantes.

- La posición antropocéntrica, por último, no está para nada ausente de problemas internos. Ella se articula, en la literatura corriente, como posición de principio, olvidando tal vez que cada forma de antropocentrismo es siempre mediada simbólicamente. La relación que el hombre mantiene con el ambiente natural se formula siempre en términos metafóricos. A través de las metáforas damos significado a tal relación, conferimos valor a singulares formas de relación y gozamos, al mismo tiempo, estéticamente de ello.

Todas estas debilidades argumentativas llevan a una ulterior interrogante. ¿Debemos continuar construyendo un sistema de normas para regular nuestra relación con el ambiente natural $a$ partir de un solo argumento que haga, por así decirlo, de soporte de todo el edificio argumentativo, o bien debemos resolver los conflictos normativos caso a caso, escogiendo en el abanico de argumentos posibles aquéllos que en mayor medida nos parezcan convenientes? Debemos descartar tal alternativa, pues es insidiosa en ambas variantes, debiendo, más bien, buscar una respuesta mediana. Esta última, puede y debe orientarse a diversos principios, aunque relevantes en el contexto de los conflictos singulares, pero al mismo tiempo debe poder jerarquizarlos, para así legitimar las elecciones de manera plausible para la mayor parte de los interlocutores. ¿Qué significado puede asumir tal trabajo teórico para la actividad sociopolítica y para los actores responsables en los diversos sectores de la vida pública? Es lo que trataré de evidenciar ahora, en la última parte de este estudio.

\section{De la reflexión de fondo a la elaboración concreta de las elecciones morales colectivas en el campo ambiental}

Aquél que en la vida política es llamado a preparar y a poner en práctica decisiones concretas, manifiesta $-\mathrm{y}$ seguramente no sólo en los últimos tiempos, sino que ya desde hace siglos, si no milenios- la tendencia a querer desligar este momento de la decisión política de aquél de la valoración moral que tiene lugar en filosofía o, respectivamente, en teología. La cuestión ambiental ha hecho todavía más dramática esta separación clásica entre ética y política y ha provocado respuestas todavía más radicales, tanto en el sentido de la separación como en el de la unión entre los dos términos de la relación (69). Ciertamente no es posible retomar aquí los elementos de esta problemática tan amplia y compleja.

Pretendo, sin embargo, hacer cuando menos alusión a un aspecto particular que caracteriza la reciente discusión y, por tanto, la relación existente entre exigencias ético ambientales y la democracia como forma de autogobierno de una sociedad basada en el derecho y no simplemente en la fuerza. Esta relación ha sido problematizada por varios pensadores recientes, en primer lugar por Hans Jonas y por Vittorio Hösle (70 -74). Según Jonas, para limitarme al primer ejemplo, los desafíos provocados por la crisis ambiental y por los nuevos poderes científicos del hombre sobre los procesos naturales, son de una gravedad y de una urgencia tales que no permiten una discusión democrática $a d$ infinitum, hasta que se haya formado un consenso mayoritario e internacional. En el intertanto, las élites políticas ejercitan una responsabilidad frente a los ciudadanos presentes y futuros en una forma casi patriarcal $(75,76)$. Ellos tienen que poder garantizar la protección y el goce de los bienes primarios mediante una abstención preventiva frente a los proyectos de carácter riesgoso. La ética política de Jonas da a los decisores sociales una competencia muy limitada y negativa. Estos decisores deben ante todo preservar, más que correr y hacer correr riesgos. Ellos no deben privilegiar las eventuales generaciones futuras frente a las otras definiendo para ellas eventuales necesidades futuras, sino que tienen sólo el deber de preservarlas de daños provocados por las generaciones actuales. Jonas polemiza contra todo espíritu utopístico que ve en el futuro oportunidades no todavía disponibles en el presente y reclama la necesidad de una nueva humildad inducida por la reflexión acerca de los inmensos poderes actuales del hombre sobre la 
naturaleza y sus mecanismos íntimos. Para superar el miedo-verdadero resorte de la sensibilidad moral, hoy más que necesaria-no debemos encomendarnos a la utopía, sino que al sentido de responsabilidad frente a la posteridad.

Frente a un discurso de este tipo, digno de gran atención, pero fundamentalmente pesimista, es necesario, a mi juicio, formular principios intermedios que sin apelar ni a la heurística del miedo, por una parte, ni mucho menos a la confianza ciega en el progreso, por la otra, puedan mediar algunas evidencias operativas en sistemas democráticos todavía imperfectos. Tales principios intermedios necesitan, si pretenden tomar forma, de instrumentos jurídicos adecuados. En ambas temáticas esbozaré algunas reflexiones que, evidentemente, podrán y deberán ser ulteriormente profundizadas.

\subsection{Los denominados "derechos de la naturaleza": ¿por qué una interrogante de este tipo?}

Hablar de "derechos de la naturaleza" puede parecer, a simple vista, una pregunta particularmente retórica o, a lo menos, superflua. Si se toma algo más de distancia se verá cómo esta última constituye, por así decirlo, el corazón de los debates contempóraneos en ética ecológica o, cuanto menos, uno de los aspectos decisivos a nivel operativo.

Saber si es posible, racionalmente coherente y políticamente oportuno reconocer a la naturaleza no humana -en sus expresiones animal, vegetal y mineral- un «derecho» y cuáles son las consecuencias de tal reconocimiento, constituye un nudo importante de la discusión ético-ecológica en general. ¿Por qué surgió una interrogante de este tipo que, por lo menos a primera vista, tiende a ser percibida como "extraña» y carente de toda densidad teórica?

Un primer motivo debe buscarse tal vez no tanto en una exigencia de tipo teórico, cuanto en una urgencia dictada por el hecho de que nos encontramos frente a un vacio jurídico parcial, pero al mismo tiempo real, en el campo del derecho ambiental. Este vacío no debe ser visto sólo como una falta de normas positivas específicas, sino que también como un déficit de argumentos coherentes al fundamentar la intervención del Estado en este ámbito.

De este modo, se inmiscuyen en las discusiones marcadamente intrajurídicas las posiciones y los «frentes» propios del campo éticofilosófico, así como también las discusiones de «bioética» vinculadas a los llamados «casos marginales», es decir, a aquellos objetos o sujetos jurídicos no fácilmente clasificables en su interpretación y en la fijación de su protección jurídica concreta $(77,78)$. El discurso en torno a los llamados «derechos de la naturaleza» se enmarca en este territorio mental en continuo movimiento y en el cual se articulan diferentes disciplinas y metodologías, muy diversas entre sí. Son precisamente tales «lugares» los que reclaman al cultor de la ética una mayor prudencia cognoscitiva y valorativa.

\subsection{Algunos nudos específicos del problema}

¿Cuáles son los problemas que el derecho es llamado a dirimir en este ámbito, independientemente de los contenidos que se quieran dar a los problemas específicos de ética ecológica?

Ante todo, debemos destacar que el derecho no puede temporalmente esperar que los problemas fundantes sean resueltos de manera acabada para poder iniciar la actividad propia de regulación de conflictos concretos. Este «no poder esperar» vale también para el discurso propiamente ético, en la medida en que cada uno de nosotros es llamado a actuar antes que se hayan expuesto de manera cabal todos los argumentos que existen a favor o en contra de un comportamiento preciso. Esta urgencia explica, por lo menos en parte, la presencia de tendencias maximalistas que se manifiestan en el querer atribuir no sólo a organismos sensibles, como los animales, "derechos especificos», sino que también a entes inanimados, como «paisajes», «montañas» $\mathrm{u}$ otros.

Un segundo «nudo» para la reflexión jurídica consiste también en el carácter difuso del término "proteger» en este sector específico. Si bien todos concuerdan en la necesidad de una protección de la naturaleza, se manifiestan claros disensos acerca del sentido y alcance concreto que debe darse a tal expresión, que no puede más que tener connotaciones antropomorfas. Será tarea específica de las ciencias jurídicas clarificar el uso de esta locución o de precisarla de manera tal que no resulte permanentemente ambigua.

Una tercera dificultad de la práctica jurídica en esta esfera de la convivencia está dada por el hecho de no poder fijar claramente quién puede 
legítimamente ser «abogado» de los intereses de la naturaleza inanimada y bajo qué condiciones. No es, en efecto, suficiente proclamar la propia solidaridad con la naturaleza para transformarse en la instancia abogadora que en una sociedad determinada represente constantemente y de manera legítima los intereses de esa naturaleza.

\subsection{Argumentos en torno a los llamados «derechos de la naturaleza»}

¿Qué significa e implica que organismos naturales sean portadores de un jus subjectivum o que sean «sujetos de derecho»? Kant define este jus subjectivum como la «capacidad de provocar deberes en los demás» (79). A este respecto, por lo menos en el reino de las realidades perceptibles por los sentidos (dejamos de lado, por razones de método, a eventuales «ángeles» y a Dios), sólo el hombre como especie posee habitualmente, aunque no siempre puntualmente, tal capacidad de poder emitir deberes y ello lo hace propiamente titular directo de derechos. Me he expresado, espero, en términos bastante prudentes, evitando, intencionalmente, entrar en el ámbito de los llamados casos marginales, que dicen relación con aquellos miembros de la especie homo sapiens que no poseen puntual o habitualmente tal capacidad $(80-86)$ y que son fuente de dificultades argumentativas ulteriores.

¿En estos términos se sostiene la presencia de «derechos de la naturaleza»? La respuesta debe darse de manera diferenciada, examinando con atención los argumentos presentes en la literatura específica (87-91).

Una primera versión de los llamados «derechos de la naturaleza» utiliza consideraciones de tipo naturalista, según las cuales la humanidad misma tuvo un origen histórico desde formas menos organizadas de vida y que, por lo tanto, no es posible deducir de la pertenencia a la especie homo sapiens una posición de preeminencia frente a otras formas de vida. Tal posición ha sido sostenida particularmente por Meyer-Abich y cae, en mi opinión, en la fácil trampa de la llamada falacia naturalista (92). La simple consideración de que se pueda suponer una comunidad de vida entre formas de vida humana y el resto de la naturaleza animada e inanimada, no conduce, por lo menos prima facie, a fundar necesariamente un deber de comportamiento particular frente a esta naturaleza.
La afirmación hecha en este contexto de la radical igualdad de las variadas expresiones, humanas, animales, vegetales y minerales de la naturaleza, corre el riesgo de transformarse en una fórmula vacía, puesto que no toma en consideración el continuo dinamismo de cambio y de variación de formas presente en el cosmos. Tal dinamismo no permite ni siquiera pensar cómo se configura tal «igualdad». En otras palabras, en un contexto holístico y casi animista, hablar de derechos de la naturaleza no lleva necesariamente a una opción precisa y vinculada al actuar que se encuentre de algún modo motivada o legitimada con argumentos. En efecto, allí donde existe un fenómeno jurídico debe haber por lo menos un sujeto capaz de percibir deberes frente a terceros, vistos como objetos separados de sí y «dignos de ser objeto de responsabilidades». La referencia a la realidad de una comunidad biótica por sí sola, no está, pues, en grado de fundar tal relación de deber.

Hay incluso versiones aún más diferenciadas de los llamados «derechos de la naturaleza». Así, Beat Sitter ha tratado de insertarlos en el cuadro más global de una forma renovada de entender el programa del «derecho natural». Este autor trata de formular los principios de este derecho natural tratando de no caer en la trampa fácil de la falacia naturalista y, al mismo tiempo, busca dar a los mecanismos autorregulatorios («ecológicos») de la naturaleza una normatividad independiente de consideraciones antropocéntricas. El intento de Sitter es, a todas luces, no sólo loable sino que, además, teóricamente ambicioso. Para poder dar consistencia a su programa avanza en base a pequeños pasos argumentativos que trataré de reconstruir en forma sucinta.

En primer término, este autor observa en la historia del pensamiento filosófico y en la veta específica de la tradición del derecho natural que la justicia ha sido hasta ahora pensada como una categoría que caracteriza sólo relaciones entre hombres y entre instituciones humanas. Según Sitter, es necesario aplicar este criterio también a las relaciones entre el hombre y la naturaleza que lo rodea (93). Para hacer operativo este postulado es necesario formular un principio general, no antropocéntrico, que sea claramente aplicable a este tipo de relación. Los ecosistemas, a pesar de ser reconocibles y reconstruibles sólo por la mente humana, son independientes, en su esencia, de esta última. Así, Sitter afirma que «los ecosistemas 
subsisten independientemente de la creatividad y de la voluntad humana. Por este motivo los hombres no pueden ni crearlos ni mucho menos poseerlos» (93; p.281).

De esta observación, piensa que es posible deducir el deber del hombre de no alterar estos ecosistemas. Sitter se sirve en este punto de la categoría de propiedad, excluyendo su pertinencia para la relación con los mecanismos ecológicos. Dado que el hombre no tiene el derecho de poseer aquello que no ha creado, debemos suponer que existe un derecho a la «intangibilidad» por parte de estas realidades naturales.

Este derecho encuentra su raíz, siempre según Sitter, en una dignidad intrínseca a la naturaleza. Esta dignidad se justifica con argumentos vinculados no a la antropología filosófica, sino que a temas y argumentaciones de tipo «naturalfilosófico». La dignidad de la naturaleza es primigenia y casi la raíz de la dignidad humana misma $^{i}$. La preexistencia de derechos de la naturaleza, que preceden no sólo cronológicamente, sino que también jerárquicamente a los que el hombre ha proclamado para su propia convivencia en sociedad y, siempre según Sitter, legitimada por una posición de poder que la naturaleza tiene frente al hombre.

La propuesta de Sitter, de seguro comprensiva y generosa a nivel de las intenciones y motivaciones subyacentes, revela, sin embargo, a nivel argumentativo, algunas debilidades que no pueden ser calladas o minimizadas. Una primera debilidad está dada, a mi juicio, por la insuficiente defensa de la denominada falacia naturalista. No veo, en efecto, por qué se tiene que dar una dignidad normativa particular al hecho de que algunos mecanismos naturales han surgido sin la influencia directa de la actividad humana.

El respeto de una dignidad de este tipo

i Cfr. las afirmaciones al artículo citado, espec. 277-278. La discusión en torno a la llamada «dignidad de la creación» es particularmente virulenta en Suiza, ya que la citada locución está presente en la actual Constitución, después de una votación popular que tuvo lugar en 1992, sobre la base de un texto propuesto por el Gobierno. Actualmente, el problema jurídico se ha trasladado desde la presencia o ausencia de una locución de este tipo hacia el de su interpretación y de las normas concretas que se pueden deducir de tal fórmula. Cfr. a este respecto Vom Menschenbild der Mäuse. Gentechnologie. "Würde der Kreatur", Patente auf Leben. Boldern 1993. llevaría a la deslegitimación, extremadamente contraintuitiva, de muchas de nuestras intervenciones habituales en el cosmos. Pensemos en la construcción de vías de comunicación, en la «corrección» de los ríos, etc. Es más, el hecho puramente físico de que algunos mecanismos de la naturaleza sean más fuertes que la posibilidad de intervención del hombre sobre ellos, no fundamenta para nada el hecho de que se deba reconocer a estos mismos mecanismos la dignidad de un «derecho». Por el contrario, se habla de la existencia de un derecho allí donde el poder es limitado por consideraciones de tipo ético, que se remiten a los principios de igualdad y de justicia. La debilidad de la posición de Sitter me parece, por tanto, doble: ética y jurídica.

Cabe destacar aquí una consideración que vale también para otros autores y que expondré a continuación en este escrito. En efecto, podemos preguntarnos si es necesario proponer figuras argumentativas extremadamente «barrocas»y complejas para alcanzar resultados normativos no más concluyentes que aquellos que se podrían alcanzar a través de un antropocentrismo autocrítico. En efecto, proclamar, «derechos de la naturaleza» a partir de una visión tan fisiocéntrica, no conduce a la elaboración de criterios de acción claros, sino que sólo a la legitimación de una «no intervención». Los resultados ecológicos de esta práctica de pasividad pueden ser, en algunos casos, tan problemáticos como aquellos obtenidos a través de un intervencionismo acrítico (94).

El jurista bernés J. Leimbacher ha propuesto una visión jurídica en la cual se reconoce a la naturaleza una cuasi personalidad (95). La afirmación inicial de la cual parte Leimbacher me parece particularmente interesante, ya que destaca un elemento no explorado aún suficientemente. Se trata de la clasificación de la naturaleza entre la categoría de las cosas y la consiguiente actitud omnipotente y destructiva por parte del hombre que de ella derivaría. Este diagnóstico es interesante en la medida que pone en discusión la división entre personas y cosas no en línea de principio, sino que en su pretensión de exclusividad.

La discusión animalista, que ha influenciado directamente las posturas de Leimbacher, ha relativizado esta división o, por lo menos, ha evidenciado que es necesaria la introducción de categorías «mixtas» ulteriores que sirvan para determinar mejor la clase de bien jurídico que debe 
ser protegido, a partir de consideraciones de tipo ético. Me doy cuenta perfectamente de la dificultad ínsita en tal multiplicación de las categorías jurídicas. La división binaria «cosas-personas» tenía en su brutalidad la ventaja de evocar consecuencias claras a nivel de comportamiento humano.

No obstante este aspecto positivo vinculado a la propuesta de Leimbacher, subsisten, a mi entender, algunas perplejidades. En primer término, el jurista bernés se remite a veces a la figura de cuasi derechos y otras, habla explícitamente de la capacidad jurídico-positiva de la naturaleza, haciendo de ella un sujeto de derechos a pleno título, mientras otras veces habla sólo de deberes ecológicos por parte del hombre, mediante el aumento de la esfera de sus responsabilidades morales. Tal vez las exigencias de unidad o de coherencia argumentativa son más fuertes en ética normativa que en el campo del derecho constitucional, en el cual se mueve precisamente Leimbacher. En todo caso, no me parece posible sostener al mismo tiempo posiciones fisiocéntricas $\mathrm{y}$, cuando las posibilidades de fundamentación se revelan complejas, pasar al registro antropocéntrico o pathocéntrico.

Sin embargo, la investigación de Leimbacher tuvo el mérito de hacer avanzar la discusión jurídica, especialmente en el sentido de superar la percepción jurídica de la naturaleza como mera cosa, objeto de propiedad, que, como bien sabemos, ha sido definida hasta ahora como jus utendi et abutendi. Se busca proponer categorías aptas para circunscribir mejor los deberes que los individuos y la sociedad tienen en relación con la naturaleza.

\subsection{Méritos y límites de la discusión}

En primer término, debemos destacar la cuasi unanimidad alcanzada en torno al hecho de que la relación hombre-naturaleza debe ser gestionada a partir de principios morales, análogamente a cuanto se ha afirmado acerca de las relaciones interpersonales y de las relaciones societarias. Esta ampliación de la esfera de la responsabilidad no provoca dificultades argumentativas de principio, sino que de detalle $y$, sobre todo, dificultades en la introducción de eventuales argumentos en el conjunto coherente de un sistema ético.

La actual discusión acerca de los «derechos de la naturaleza» tiene el mérito, independientemente de la pertinencia que cada uno de nosotros esté dispuesto a dar a estos argumentos, de reanimar la discusión general acerca de la extensión de la responsabilidad humana (96-98).

Este debate ha permitido, además, que exista acuerdo en torno a la importancia que tiene la categoría de justicia en la relación entre el hombre y la naturaleza. Las opiniones difieren -y no podría ser de otra forma- sobre cómo esta relación debe ser fundada y motivada. Pero este acuerdo implica, como consecuencia beneficiosa, que se pueda hablar con propiedad de derecho ecológico (99) en sentido estricto y que no debamos subsumir los delitos ecológicos simplemente bajo la forma de atentados a la propiedad privada.

El debate mencionado ha puesto en evidencia, además, cómo la relación entre hombre y naturaleza no sólo no es plenamente recíproca, sino que se encuentra caracterizada cada vez más por un cambio radical. Hasta la revolución industrial, la naturaleza era para el hombre lugar de necesidad y límite a su libertad; en la actualidad, la relación se ha dado vuelta, al punto de que la naturaleza se ha transformado en instancia de total disponibilidad para el hombre, o mejor dicho, ella es, subjetivamente, así percibida. Esta percepción debe ser corregida por la constatación de que «la naturaleza se rebela», es decir, sufre mutaciones que tienen consecuencias negativas para la calidad de la convivencia misma.

Todos estos elementos caracterizan de manera positiva la discusión suscitada. A partir de éstos será posible en el futuro una mayor concretización, tanto a nivel específicamente filosófico como jurídico. Un examen atento de la discusión ha puesto en evidencia, además, que algunos argumentos a favor de los «derechos de la naturaleza» son válidos sin ninguna dificultad para el reino animal o, cuando menos, para la relación entre hombres y animales «superiores» o capaces de dolor fisiológico. Estos argumentos no son, no obstante, fácilmente extendibles a la naturaleza inanimada, considerada en su más amplia generalidad. Deben ser precisadas, con ocasión de esta discusión académica, las relaciones entre «ética animalista»y «ética ecológica». Si bien los argumentos, por una parte, se sobreponen, por otra, manifiestan una irreducible especificidad (100).

La discusión, más allá de estos méritos indesmentibles, se encuentra, sin embargo, caracterizada por dificultades y por límites que deben ser examinados con benevolencia y cuidado, 
de manera tal de no botar al niño junto con el agua sucia del baño. Trataré, por lo tanto, de criticar las diversas tentativas de proponer «derechos para la naturaleza» de manera tal que no produzca una disminución de plausibles deberes para nuestra generación, pero que, al mismo tiempo, no comprometa a éstos a causa de argumentaciones demasiado débiles.

Una primera impresión incontrolable que se extrae de la lectura de las posiciones enunciadas es, precisamente, la de un posible resultado normativopráctico que se puede obtener igualmente - $\mathrm{y}$ sin un esfuerzo especial - a partir de argumentaciones antropocéntricas.

Ciertamente este antropocentrismo no debe ser «naive», sino especialmente crítico, es decir, consciente del fundamental carácter metafórico de las afirmaciones que el hombre hace acerca de su relación con la naturaleza que lo rodea. Esta falta de sensibilidad es tal vez el límite más evidente de los discursos realizados en torno a los «derechos de la naturaleza». Afirmar este carácter metafórico no significa evidentemente subrayar al mismo tiempo la arbitrariedad. Por el contrario, no me parece posible distinguir materialmente entre necesidades «naturales» y necesidades «culturales» en la relación del hombre con el cosmos que lo rodea. Ambas necesidades se encuentran permanentemente conectadas y el referirse a ellas de manera metafórica, representa el tipo de lenguaje quizás más adecuado para este fenómeno (101).

Una ulterior nota negativa del mencionado debate está dada por el hecho de que los defensores de los «derechos de la naturaleza» se preocupan poco de reflexionar acerca de las condiciones en torno a las cuales puede establecerse un consenso democrático acerca de estos derechos. En mi opinión, una de las aporías más dolorosas de todo el debate ecoético contemporáneo, y que requiere respuestas bien articuladas y argumentadas, es la de la «dictadura ecológica», como vía de escape al dilema de tener que actuar a tiempo, antes de haber llegado democráticamente a un acuerdo acerca de aquello que debe hacerse y evitarse $(70 ; 102)$.

Un último límite que me parece que caracteriza a este debate, consiste en que con ocasión de la proclamación optativa de estos «derechos» nos encontramos frente a una eticización de la vida que merece, a lo menos, ser meditada críticamente. No corresponde, evidentemente, a un cultor de ética lamentarse por la creciente sensibilidad moral por aspectos de la vida que hasta ahora permanecían en la sombra. Un lamento de este tipo sería percibido como «escandaloso» y contraproducente. Por lo tanto, no debemos olvidar que pueden desarrollarse formas de rigorismo no justificadas suficientemente y que aplicadas mecánicamente a otros ámbitos de la vida paralizarían toda actividad.

Pero no se trata de esto, sino que de una consideración de fondo que no pone en discusión la justa ampliación de nuestros deberes, tampoco la relación hombre-naturaleza y a sus concretizaciones.

\subsection{De los "derechos de la naturaleza" a la "dignidad de la creación"}

Algunos estados han tratado de anticipar una tutela global del ambiente natural, introduciendo esta exigencia en las leyes y hasta en sus cartas fundamentales. En Suiza -que a este respecto ha anticipado, por medio de una votación popular, una situación que en otros países se sigue discutiendo-, el Estado se ha autoimpuesto el deber de respetar la llamada dignidad de la creación (103 -106). Más allá de las nobles intenciones que han llevado a formulaciones de este tipo, nos podemos preguntar si este modo de proceder deductivo constituye una elección óptima, sobre todo desde un punto de vista ético-social, para llegar en breve tiempo a una praxis de minimización de los daños ambientales. El hecho de haberse reconocido el carácter metafórico de la fórmula "dignidad de la creación", incluso por aquéllos que han propuesto dicha fórmula -como ocurre con Beat Sitter-Liver-, no disminuye la dificultad de su puesta en práctica directa, cuestión que ha sido objeto de crítica puntual, aunque no radical.

Personalmente pienso que es más práctico orientarse al principio de regeneración " $\mathrm{y}$, por tanto, a una interpretación estricta del denominado criterio de la Nachhaltigkeit $(107,108)$ aplicándolo "desde abajo", mirando, por tanto, las posibilidades que el ambiente tiene de cambiar, garantizando al hombre y a las demás formas de vida una continuidad, más allá de la temporalidad de los individuos singulares, y partir de otros principios "intermedios" que no pretenden tener el mismo carácter de absoluto que sugiere la categoría de "dignidad".

En efecto, esta última ha requerido -en aquellos lugares donde ha sido introducida en el texto constitucional-, el establecimiento de un 
"Comité Nacional de Ética" que garantice la concretización. Éste, después de laboriosas discusiones, no ha llegado a un consenso en torno a la fórmula de la "dignidad de la creación", sino sólo a un acuerdo sobre algunas prácticas que deben ser reguladas concretamente. En otras palabras, una fórmula demasiado abstracta corre el riesgo de surtir el efecto contrario a aquél que se esperaba con esta introducción terminológica en el texto constitucional.

\section{Algunos principios intermedios}

Debemos destacar, en primer término, cómo la cuestión de la competencia del hombre en este ámbito necesita una justificación que vaya más allá de las que han sido tradicionalmente divulgadas hasta ahora.

\subsection{El principio de "sustentabilidad"}

El principio más clásico en el ámbito de la ética ambiental es el de sustentabilidad, atributo necesario de cada proceso de cambio y de desarrollo humano en relación al ambiente natural. El acuerdo verbal en torno a este principio es mucho más amplio, ya a partir de fines de los años '70 (109), pero, no obstante, todavía muy vago $\mathrm{y}$, al mismo tiempo, controvertido.

Un primer elemento que facilita la concretización del término está dado por la dimensión del futuro. Será considerada como "sustentable" aquella intervención o aquel modelo de desarrollo que esté en condiciones de garantizar un futuro, tanto a un ambiente preciso (bosque, lago, etc.), como a una forma de producción agrícola. Un segundo elemento definitorio, muy cercano al anterior, está dado por la capacidad autorreproductiva de elementos singulares de la naturaleza. Será sustentable aquella intervención que dé a cada planta o animal la posibilidad de autorreproducirse de manera armónica en un determinado territorio. No es, por tanto, casualidad que esta categoría haya nacido al interior del vocabulario de las ciencias forestales. Así, si hacemos referencia a hábitat complejos, con la presencia de animales diversos, se plantea el problema de saber si la presencia "nueva" de particulares especies animales puede o no ser considerada parte de un desarrollo "sustentable". Esta biodiversidad podría ser, por ejemplo, en una perspectiva antropocéntrica, no siempre "sustentable". Los debates en las zonas alpinas acerca de la reintroducción, más o menos espontánea, de algunas especies animales, como por ejemplo el oso y el lobo, ponen de manifiesto claramente cómo esta categoría no siempre es apta para servir de apoyo a decisiones normativas que se justifican, quizás, tomando en consideración otros criterios.

Una ventaja evidente de esta categoría consiste, de todas maneras, en haber ayudado a la discusión ecológica a salir del estrecho ámbito de una consideración puramente intraecológica para colocarse como elemento de una ética económica más global, que dice relación con cada proceso productivo humano (110).

Un ulterior elemento prudencial del criterio de sustentabilidad es el de una cierta "retinitá" (111), es decir, de un autolimitarse como actitud preventiva frente a una producción no atenta a las consecuencias fácticas de las inversiones económicas, en el ambiente natural. A propósito de este nuevo principio de fondo de la convivencia social, se está desarrollando todavía un debate, cuando menos controvertido, que trata de clarificar el problema vinculado a la necesidad o no de institucionalizar una autolimitación del Estado en sus finalidades y actividades vinculadas a la interacción hombrenaturaleza.

\subsection{El principio de la prioridad de la prevención por sobre la reparación}

Las experiencias acumuladas en estos últimos decenios han convencido, tanto a aquéllos que reflexionan acerca de los fundamentos del actuar humano (filósofos y teólogos) como a los operadores socio-políticos, de que es prioritario prevenir los daños ambientales más que su reparación ex post. Esta convicción se ha ido consolidando al constatar que los tiempos del daño y de la reparación son extremadamente diferentes entre sí. Los primeros pueden ser brevísimos, mientras que los segundos son casi siempre tremendamente lentos. Esta diversidad se torna significativa también a nivel moral, si se considera que la diversidad de los tiempos provoca indirectamente una disminución del sentido de responsabilidad. En general, la generación que paga por los daños es distinta de aquélla que los provocó y, por ende, la confrontación y el conflicto directo se ven, por así decirlo, excluidos. También los instrumentos jurídicos se revelan ineficaces, 
puesto que la muerte de los actores excluye la posibilidad de poder sancionarlos penal o civilmente. Frente a esta trágica situación, no queda más que concentrar los esfuerzos en la urgencia moral y política de la prevención activa. Debemos también reflexionar acerca de la posibilidad de que el derecho encuentre una figura de responsabilidad por falta de prevención, tal como ha sucedido en otros ámbitos, como, por ejemplo, en el caso de la "omisión de socorro a persona necesitada".

Evidentemente, también la prevención está sujeta a límites estructurales; así, la percepción del peligro ambiental está limitada por los conocimientos disponibles en un determinado contexto de espacio y de tiempo. No tendría sentido, por ejemplo, reprochar a las generaciones de la primera mitad del siglo pasado el no haber tomado medidas en relación con el "hoyo de ozono", mientras que este reproche es absolutamente pertinente hoy en día, aunque las generaciones futuras no podrán llevar a los tribunales a los miembros de los gobiernos contemporáneos.

\section{3 "El que rompe paga"}

Frente a tales aporías no queda más que aplicar un principio más practicable, por lo menos en la situación actual. Éste puede encontrarse en el intento de objetivar la presencia de un daño ambiental, no vinculado simplemente a sentimientos individuales o colectivos de malestar, sino que localizable claramente en una situación comparable con un status quo ante. Con el fin de que este postulado pueda ponerse en práctica, es necesario un conocimiento preciso de los datos empíricos del momento actual. Pensemos, para ilustrar la problemática, en el daño provocado a las aguas de los mares de Alaska por parte de naves que han transitado negligentemente por ellas. Podrá certificarse un daño preciso sólo en la medida en que se tengan datos ciertos acerca del estado de estas aguas antes de los hechos. A falta de ellos, el reproche podrá, no obstante, ser efectuado a nivel moral, pero no podrá tener eficacia jurídica, ante la imposibilidad de corroborar las pruebas empíricas. En otras palabras, la amenaza de sanciones es eficaz sólo en presencia de observación empírica continua de estos factores considerados significativos para la calidad de un ambiente natural, con sus elementos fundamentales como el aire, el agua y la temperatura ambiental.
El principio "el que rompe paga" no debe ser comprendido y aplicado sólo en sentido negativo, como amenaza de sanciones. Tiene también una connotación positiva, en cuanto exigencia de contribuir en términos financieros por parte de todos aquellos que tienen acceso comprobado a bienes ambientales $(112,113)$, hasta ahora considerados ilimitados y, por ende, res nullius. A este respecto, a pesar de los esfuerzos realizados, tanto a nivel nacional como internacional, estamos recién dando los primeros pasos. Un impuesto general sobre la energía o sobre determinados elementos de ella (como, por ejemplo, sobre el consumo de anhídrido carbónico), encuentra todavía muchas oposiciones, tanto a nivel de principios como en su aplicación práctica (114). A pesar de ello, pienso que debemos considerar como éticamente necesario solicitar a todas las personas estas contribuciones, puesto que la reparación de los daños causados por el consumo de elementos naturales recaerá injustamente sobre personas que no los han causado directamente. El instrumento del impuesto pecuniario es el más rápido en el sucederse de las generaciones. Para facilitar de manera positiva un consumo menos dañino de energías ambientales, las comunidades políticas pueden y deben recurrir también al instrumento de la subvención, sometiéndola, no obstante, a una valoración recurrente, ya que el hombre siempre tiende a desnaturalizar el sentido primigenio de una intervención legislativa, para ponerla al servicio de egoísmos personales o colectivos.

\subsection{La necesidad de la cooperación}

El llamado principio de subsidiaridad no deja en absoluto de ser pertinente en este ámbito, a pesar de haberse tomado conciencia de que toda transformación en el ambiente natural es de por sí global y no se reduce a los límites artificiales de las sociedades organizadas en Estados. En otras palabras, las políticas ambientales deben ser realizadas y organizadas con los actores más cercanos a las causas del malestar ambiental.

Por otra parte, la llamada crisis ecológica ha hecho fracasar -más que muchas filosofías internacionalistas de los siglos pasados-el principio de la soberanía nacional como medida de una responsabilidad política colectiva $(115-118)$. Ha sido superado en el sentido de que los Estados tienen una responsabilidad que va más allá de sus fronteras, como también en el sentido de una responsabilidad 
de los individuos y de los grupos frente a la humanidad toda.

Las organizaciones internacionales, por su parte, en la medida que les sean dadas las posibilidades de intervenir y los medios para poder funcionar, tienen también deberes precisos en el ámbito de las políticas ambientales (119). En este ámbito estamos recién en los inicios, especialmente en lo que se refiere a las posibles sanciones para los Estados que no respeten los acuerdos internacionales en materia ambiental.

\section{Conclusiones}

Como puede apreciarse a partir de las breves consideraciones de estas últimas páginas, el trabajo que espera a aquellos que pretenden ocuparse de ética del ambiente es aún inmenso, a causa de la complejidad de los fenómenos que nos rodean y de las exigencias teóricas vinculadas a las argumentaciones éticas "limpias".

Estas últimas tienen que ser posibles sobre todo en un mundo en el cual, por una parte, la casa común se vuelve cada vez más pequeña y familiar y, por la otra, gracias al respeto de la autonomía de los sujetos individuales, siempre más pluralista en las visiones de la naturaleza y del mundo mismo.

Será necesario tratar de mantener juntas ambas exigencias, la de un pluralismo de visiones del mundo, que permanece irreducible, si no queremos limitar la libertad de pensamiento y de religión, y aquélla de un ethos común, más allá de las distintas mentalidades y sensibilidades. 


\section{Referencias}

1. Bartolommei S. Etica e ambiente: il rapporto uomo-natura nella filosofia morale contemporanea di lingua inglese. Milano: Guerini \& Associati; 1989.

2. Bartolommei S. Etica e natura: una "rivoluzione copernicana" in etica?. Bari: Laterza; 1995.

3. Privitera S (comp). Per un'etica dell'ambiente. Roma: Armando Editore; 1995.

4. Privitera S. Etica dell'ambiente. Napoli: Guida Editore; 1994.

5. Poli G (comp). Etica ambientale, teoria e pratica. Milano: Guerini; 1994.

6. Auer A. Etica dell'ambiente. Brescia: Queriniana; 1988.

7. Nida-Rümelin J. Etica ecologica. Il Mulino 1988; 37:768- 85.

8. Schopenauer F. Preisschrift über die Grundlage der Moral. In: Kleinere Schriften III., Frankfurt/M: Verlag Suhrkamp; 1989; p. 629.

9. Bondolfi A. Etica applicata. Cenobbio 1995; 2: 279-89.

10. Apel KO, Kettner M (comp). Zur Anwendung der Diskursethik in Politik, Recht und Wissenschaft. Frankfurt n/M: Surhkamp Verlag; 1992.

11. Heeger R, Van Willigenburg T (comp). The turn to applied ethics: practical consequences for research, education and the role of ethicist in public debate. Kampen: Kok Pharos; 1993.

12. Bondolfi A. Momenti del dibattito tedesco sull'etica. In: Religione e Società, 2 [1986]. pp. 38-56

13. Viafora C. Vent'anni di bioetica nell'area linguística tedesca. Padova: Gregoriana; 1990.

14. Scüller B. La fondazione dei giudizi morali. Asisi: Cittadella; 1975.

15. Privitera S. Il volto morale dell'uomo. Avvio allo studio dell'etica filosofica e teologica. Palermo: Oftes; 1991.

16. Schmitz P. Kasuistik. Ein wiederentdecktes Kapitel der Jesuitenmora. Theologie und Philosophie 1992; 67: 29-59.

17. Denmer K. Erwägungen über den Segen der Kasuistik. Gregorianum 1982; 63: 133-40.

18. Jonsen R, Toulmin ST. The abuse of casuistry. A history of moral reasoning. London: University of California Press; 1988.

19. Stivers R. Christian ethics. A case method approach. Mariknoll: Orbis Book; 1989.

20. Christoffer U. Erfahrung und Induktion. Zar Methodenlehre philosophischer und theologischer Ethik. Freiburg i. Ue.-Freiburg i. Br.: Universitätsverlag-Herder Verlag; 1989.

21. Mieth D. Erfahrung und Moral. Freiburg i. Ue.- Freiburg i. Br.: Universitätsverlag-Herder Verlag; 1993.

22. Privitera S. Dall'esperienza alla morale. Palermo: Oftes; 1985.

23. Cortella L. Aristotele e la razionalità della prassi. Una analisi del dibattito sulla filosofia pratica aristotélica in Germania. Roma: Jouvence; 1987.

24. Thiebaut C. Neoaristotelismos contemporáneos. En: Thiebaut C (ed). Concepciones de la ética. Madrid: Trotta 1992. pp. 29-51.

25. Apel Von K.-O, Kettner M. Zur Anwendung der Diskursethik in Politik, Recht und Wissenschaft. Hrsg. Frankfurt am Main: Suhrkamp Verlag; 1992.

26. Günther K. Der Sinn für Angemessenheit. Anwendungsdiskurse in Moral und Recht. Frankfurt am Main: Suhrkamp Verlag; 1988.

27. Ricœur P. Herméneutique et critique des idéologies. In: Castelli E (ed). Demitizzazione e ideologia. Padova: Cedam; 1973, pp. 25-61.

28. Kramer W. Applikation. Historisches Wörterbuch der Philosophie 1986 ;1: 457-58.

29. Korff W. Norm und Sittlichkeit. Untersiichangen zur Logik der nomativen Vernunft. Mainz: Grünewald Verlag; 1973.

30. Carcaterra G. Il problema della fallacia naturalistica. Milano: Giuffrè; 1968.

31. Wiedmann F, Biller G. Klugheit . Historisches Wörterbuch der Philosophie. Umgang mit Normen. Mainz: Grünewald Verlag; 1983.

32. Bondolfi A. Bioéthique et éthique écologique: un défi pour l'Europe. Le Supplément 1995; 5: 161-72. 
33. Groh D. Weltbild und Naturaneignung: zur kulturgeschichte der natur. Frankfurt/M: Suhrkamp Verlag; 1991.

34. Böhme G. Natürlich Natur. Über Natur im Zeitalter ihrer technischen Reproduzierbarkeit. Frankfurt/M: Suhrkamp Verlag; 1992.

35. Eder E. Die Vergesellschaftung der Natur. Frankfurt/M: Suhrkamp Verlag; 1988.

36. Musu I. Uomo e natura verso il nuovo millennio. Religioni, filosofia, scienza. Actas, Colloquio Internacionale. Bologna: 1999.

37. Liedke G, Picht G. Humanökologie und Umweltschutz. vol. 8. Frankfurt/M: Klett Verlag nel; 1972.

38. White L. Le radici storico-culturali della nostra crisi ecologica. Il Mulino 1973; 226: 251-63.

39. White L. The historical roots of our ecological crisis. Science 1967; 155: 1203-07.

40. Halter H, Lochbühler W. Ökologische Theologie und Ethick. 2 vol. Graz: Styria Verlag; 1999.

41. Münk HJ. Umweltkrise - Folgeund Erbe des Christentums? Hystorisch-systematische Überlegungen zu einer umstrittenen These im Vorfeld ökologischer Ethik. Jahrbuch für christliche Sozialwissenschaften 1987; 28: 133-206.

42. Lochbühler W. Führte uns das Christentum in die Umweltkrise? Theologische Stellungnahmen zu einer umstrittenen geistesgeschichtlichen These. In: Holderegger A (ed). Ökologischer Ethik als Orientierungswissenschaft. Von der Illusion zur Realität. Freiburg i. Ue: Universitätsverlag; 1997. pp. 213-41.

43. Amery C. Das Ende der Vorsehung. Die gnadenlosen Folgen des Christentums. Hamburg: Reinbek Verlag; 1972.

44. Drewermann E. Der tödliche Fortschritt. Von der Zerstörung der Erde und des Menschen im Erbe des Christentums. $6^{\mathrm{a}}$ ed. Regensburg: Pustet; 1990.

45. Krolzik U. Umweltkrise - Folge des Christentums. Stuttgart: Kreuz Verlag; 1979.

46. Krolzyk U. Säkularisierung der Natur. Providentia-Dei-Lehre und Naturverständnis derFrüaufklärung. Neukirchen: Neukirchener Verlag; 1988.

47. Lochbühler W. Führte uns das Christentum in die umweltkrise?. In: Holderegger A (ed). Theologische stellungnahmen zu einer umstrittenen geistesgeschichtlichen these. Feiburg i.UE: Universitätsverlag; 1997. pp.213-41.

48. Lochbühler W. Christliche Umweltethik. Bern: Peter Lang Verlag; 1996.

49. Kittsteiner HD. Die Entstehung des modernen Gewissens. Frankfurt/M: Insel Verlag; 1991.

50. Caplanica A. Il filosofo e la catastrofe. Un terremoto del settecento. Torino: Einaudi; 1985.

51. Beck U. Gegengifte: die organisierte Unverantwortlichkeit. Frankfurt/M: Suhrkamp Verlag; 1989.

52. Roberts L, Weale A (comp). Innovation and environmental risk. London: Belhaven; 1991.

53. Schmid M (comp). Leben in der Risikogesellschaft: der Umgang mit modernen Zivilisationsrisiken. Karlsruhe: Müller Verlag; 1989.

54. Perrow Ch. Normale Katastrophen: die unvermeidbaren Risiken der Grosstechnik. Frankfurt/M: Campus Verlag; 1989.

55. Schüz M (comp). Risiko und Wagnis: die Herausforderung der industriellen Welt. Pfullingen: Neske Verlag; 1990.

56. Lenk H (comp). Technik und Ethik. Stuttgart: Reclam Verlag; 1994.

57. Abele H. Was für eine Ethik braucht die Informatik. Forum Engelberg 1992. Engelberg: 1992.

58. Abele H. Ethique et informatique, une illusion virtuelle?. Variations herméneutiques 1998; 8: 4352.

59. Schröter MW. Mensch, Erde, Recht. Grundfragen ökologischer Rechtstheorie. Baden-Baden: Nomos Verlag; 1999.

60. Nida-Rümelin J, Pforten van den D. Ökologische Ethik und Rechtstheorie. Baden-Baden: Nomos Verlag; 1995.

61. Pforten van den D. Ökologische Ethik. Zur Rechtfertigung menschlichen Verhaltens gegenüber der Natur. Reinbek: Rowohlt Verlag; 1996.

62. Bondolfi A. Primum non nocere. Comano: Alice Editore; 1992.

63. Morris DB. The culture of pain frühaufklärung. Neukirchen: Neukirchener Verlag; 1988.

64. Morris DB. The culture of pain. California: University of California Press; 1991. 
65. Natoli S. Esperienza del dolore: le forme del patire nella cultura occidentale. Milano: Feltrinelli; 1989.

66. Leone S. Oltre il dolore. Palermo: Oftes; 1992.

67. Brodniewicz J. Über das Schmerzphänomen. Bern: Lang Verlag; 1994.

68. Malacrida R (comp). Verso una società indolore: le aporie del dolore contemporaneo. Comano: Alice Editore; 1992.

69. Bobbio N. Etica e politica y Ragion di Stato e democrazia. In: Bobbio N. Elogio della mitezza. Milano: Linea d'ombra Editore; 1994, pp. 67-120.

70. Jonas H. Il principio di responsabilità. Torino: Einaudi; 1990.

71. Böhler D (comp). Ethik für die Zukunft. Im Diskurs mit Hans Jonas. München: Beck Verlag; 1994.

72. Hottois G, Pinsart MG (comp). Hans Jonas: nature et responsabilité. Paris: Vrin; 1993.

73. Müller D, Simon R. Nature et descendence: Hans Jonas et le principe de responsabilité. Genève: Labor et Fides; 1993.

74. Römelt J. Theologie der Verantwortung. Innsbruck: Resch Verlag; 1991.

75. Gerhardt V. Das Prinzip der Verantwortung. Zur Grundlegung einer ökologischen Ethik. Eine Entgegnung auf Hans Jonas. In: Gerhardt V, Krawietz W(comp). Recht und Natur. Berlin: Duncker \& Humblot; 1992. pp. 103-31.

76. Vitale E. Il politico secondo Jonas: un genitore quasi perfetto. Teoría política 1990; 6: 147-54.

77. Bondolfi A. Statuto dell'embrione: considerazioni di metodo. Rivista di teologia morale 1991; 23: 223-41.

78. Kant I. Die metaphysik der sitten. Frankfurt : Akademie Ausgabe; 1980.

79. Castignone S. I diritti degli animali: prospettive bioetiche e giuridiche. Bologna: Il Mulino; 1982.

80. Kaufmann A. I diritti degli animali: prospettive bioetiche e giuridiche. Bologna: Il Mulino; 1982.

81. Castignone S. Rechtsphilosophische Aspekte wissenschftlicher Tierversuche. In: W. Hardegg y G. Preiser (comp). Tierversuche und Medizinische Ethik. Hildesheim: Olms Verlag; 1986. pp.118-58.

82. D'Agostino F. Il diritti degli animali. Rivista internazionale di filosofia del diritto 1994; 71: 78-104.

83. Pocar V. Gli animali come soggetti di diritti e la legislazione italiana. Materiali per una storia della cultura giuridica 1994; 24: 217-30.

84. Baccarini E. Filosofie dell'animalità. Milano: Giuffré; 1992.

85. Cavalieri P. La questione animale: per una teoria allargata dei diritti umani. Torino: Bollati Boringhieri 1999.

86. Birnbacher N. Rechte des Menschen oder Rechte der Natur?. Studia Philosophica 1990; 49: 61-80.

87. Leimbacher J. Die Rechte der Natur. Basel: Helbling \& Lichtenhahn; 1988.

88. Meyer-Abich. Schöpfung als Rechtssubjekt? In: Saladin P, Zenger AC (eds). Rechte künftiger Generationen. Basel: Helbling \& Lichtenhahn; 1988.

89. Sitter-Liver B. Das Recht der Natur im Naturrecht der Gegenwart. In: Heyen V (ed). Vom normativen Wandel des Politischen. Berlin: Duncker \& Humblot 1984. pp.145-72.

90. Stone D. Should trees have standing: toward legal rights for natural objects. Southern California Law Review 1975; 45: 450- 58.

91. Carcaterra G. La fallacia naturalistica. Milano: Giuffré; 1969.

92. Sitter-Liver B. Würde der Kreatur. Eine Metapher als Ausdruck erkannter Verpflichtung. Philosophisches Jahrbuch 1999; 3: 465-78.

93. Lenk H. Verantwortung für die Natur: gibt es moralische Quasirechte von oder moralische Pflichten gegenüber nichtmensch1 ichen Naturwesen?. Allgemeine Zeitschrift für Philosophie 1983; 8 (3): 1-18.

94. Leimbacher J. Die Rechte der Natur. Evangelische Theologie 1990; 8: 450-59.

95. Birnbacher N. Verantwortung für zukünftige Generationen. Stuttgart: Reclam Verlag; 1988.

96. Saladin P, Zenger A. Rechte künftiger Generationen. Basel: Helbling \& Lichtenhahn Verlag; 1988.

97. Pontara L. Etica e generzioni future. Bari: Laterza; 1995.

98. Steinberg R. Der ökologische Verfassungsstaat. Frankfurt/M: Suhrkamp Verlag; 1998.

99. Becchi P. I doveri dell'uomo nei confronti della natura. Congetture sull'etica di Kant. Materiali per una storia della cultura giuridica 1989; 19: 85-94. 
100. Battisti S. Naturrecht-Recht der Natur?. In: Muck O (ed). Sinngestalten: Metaphysik in der Vielfalt menschlichen Fragens. FS für E. Coreth. Innsbruck-Wien: Tyrolia Verlag; 1989. pp. 281-92.

101. Jonas H. Scienza come esperienza personale. Brescla: Morcelliana; 1992.

102. Bondolfi A. I cosiddetti diritti della natura: fondamento di una politica ecologia coerente. Roma: Armando Editore; 1995.

103. Teutsch GM. Die "Würde der Kreatur". Bern: Haupt Verlag, 1995.

104. Prætorius I, Saladin P. Die Würde der Kreatur. Bern: BUWAL; 1996.

105. Bondolfi A, Lesch W, Pezzoli-Olgiati D (comp). "Würde der Kreatur”. Essays zu einem kontroversen Thema. Zürich: Pano Verlag; 1997.

106. Böhm HP, Gebauer H, Irrgang B (comp). Nachhaltigkeit als Leitbild für Technikgestaltung. Röll: Dettelbach; 1996.

107. Vornholz G. Zur Konzeption einer ökologisch tragfähigen Entwicklung: eine ökonomischtheoretische Analyse der natürlichen Lebensgrundlagen. Marburg: Metropolis Verlag; 1993.

108. Schanz H. Forstliche Nachhaltigkeit. Sozialwissenschaftliche Analyse der Begriffsinhalte undfunktionen. Feiburg i.UE: Universitätsverlag; 1996.

109. Münk HJ. Starke` oder, schwache' Nachhaltigkeit? Theologisch-ethische Überlegungen zur ökologischen Grundkomponente des Sustainability-Leitbilds. Zeitschrift für evangelische Ethik 1999;43: 277-93.

110. Münk HJ. Retinität als neues Sozialprinzip? In: Auf neue Art Kirche sein. Bernward: Don Bosco Verlag; 1999. pp. 540-50.

111. Scimemi G. Sviluppo sostenibile e politiche ambientali. In: Bruzzo A, Poli C (comp). Economia e politiche ambientali. Milano: Angeli; 1996. pp. 17-23.

112. Bresso M. Analisi economica degli strumenti per la politica ambientale. In: Bruzzo A, Poli C (comp). Economia e politiche ambientali. Milano: Angeli; 1996. pp. 25-43.

113. Brown P. Responsabilità fiduciarie ed effetto serra. In: Poli C (comp). L'etica nelle politiche ambientali. Padova: Gregoriana-Fondazone Lanza; 1991. pp. 287-324.

114. Bonanate L. Etica e politica internazionale. Torino: Einaudi; 1992.

115. Bonanate L. I doveri degli Stati. Bari: Laterza; 1994.

116. Oppenheim FE. Il ruolo della moralità in politica estera. Milano: Angeli; 1993.

117. Ferrajoli L. La sovranità nel mondo moderno. Milano: Anabasi; 1995.

118. Musu I. Efficienza ed equanimità nella cooperazione ambientale internazionale. In: Poli G (comp). Etica ambientale. Teoria e pratica. Milano: Guerini; 1994. pp.135-58. 